REVISTA ANDALUZA DE ANTROPOLOGÍA

NÚMERO 15: ACTIVIDADES TURÍSTICAS, CIUDAD Y PATRIMONIO CULTURAL: MIRADAS CRÍTICAS. TOURIST ACTIVITIES, CITY AND CULTURAL HERITAGE: CRITICAL GLANCES SEPTIEMBRE DE 2018

ISSN 2174-6796

[pp. 222-226]

http://dx.doi.org/10.12795/RAA.2018.15.12

\title{
GASCÓN, JORDI y MILANO, CLAUDIO (2017). El turismo en el mundo rural ¿Ruina o consolidación de las sociedades campesinas e indígenas? Tenerife: PASOS Edita, 202 pp.
}

\author{
Raúl Travé Molero y Pablo Díaz Rodríguez \\ Ostelea-URJC
}

Los investigadores Jordi Gascón y Claudio Milano coordinan esta compilación de casos de estudio que fueron presentados en el II Congreso Internacional de Antropología AIBR celebrado en Barcelona en septiembre de 2016. El hilo conductor del libro es la pregunta que Milano y Gascón nos plantean en el título El turismo en el mundo rural ¿Ruina o consolidación de las sociedades campesinas e indígenas? o como argumentan en la introducción el Dilema de la dualidad. Un 'dilema' que aborda la histórica oscilación, aún hoy, de la academia entre las plataformas 'apologética' y 'precautoria' que definiera Jafar Jafari (1990).

La historia de la antropología del turismo está, de hecho, atravesada por esta disyuntiva. Por un lado, los análisis e interpretaciones optimistas de los efectos del turismo -motor de desarrollo, estrategia de empoderamiento de la mujer, herramienta contra la pobreza, etc. En las antípodas, las investigaciones que enfatizan sus impactos negativos- mecanismo de empobrecimiento y dependencia, de consolidación y aumento de desigualdades de género, de liquidación de actividades y economías tradicionales, etc.

Los responsables de este libro se proponen ofrecer un espacio de reflexión -un salto a la plataforma 'científico-céntrica' de Jafari- que sirva para crear "marcos de interpretación explicativos". La lectura de los nueve casos presentados anima efectivamente esta reflexión, aunque quede, inevitablemente, abierta. 
En la introducción, "Turismo y sociedad rural, o el extraño caso del doctor Jekyll y Mr. Hyde", Gascón y Milano ofrecen tres hipótesis, no excluyentes, que ayudan a pensar sobre las causas de este extraño síndrome 'esquizofrénico', comparable con el del protagonista de la célebre novela de Robert Louis Stevenson. Estas hipótesis permean los nueve capítulos que componen el libro.

La primera hipótesis es la de la diferencia: un mismo modelo genera efectos diferentes en función del contexto. Con ella se refuerza la necesidad de etnografiar para intervenir con eficacia en vez de aplicar modelos generales.

La segunda nos lleva a la reflexión epistemológica: la mirada del investigador puede estar sesgada por sus convicciones teóricas, presentando determinados efectos como positivos o negativos, más por los presupuestos desde los que se parte que por una pretendida objetividad. La reflexión sobre esta hipótesis nos obliga a exigir cierta honestidad epistemológica en la presentación y discusión de marcos teóricos y sesgos políticos y personales de los investigadores.

La tercera hipótesis manejada es la metodológica: Gascón y Milano se preguntan si el dilema de la dualidad puede ser resultado de la fase del 'Ciclo de Vida de los Destinos Turísticos' (Butler, 1980) durante la que se realiza la etnografía. Esta posibilidad anima a pensar sobre la dinámica cambiante de los contextos de estudio y señala la exigencia de realizar estudios diacrónicos.

Abren el volumen los textos de Esteban Ruiz-Ballesteros, "Turismo de base local, sostenibilidad y resiliencia socio-ecológica" y de Pilar Espeso-Molinero y María José Pastor-Alfonso "Turismo indígena: concepto y características de una actividad en auge". Ambos suponen las aportaciones más teóricas de este volumen. Ruiz Ballesteros utiliza los ejemplos ecuatorianos de Floreana, en las Galápagos, y Agua Blanca, en Manabí para plantear la utilidad del concepto de 'resiliencia socio-ecológica' (la capacidad de un sistema socio-ecológico para mantenerse acoplado en contextos de transformación), como marco analítico para medir los efectos del llamado Turismo de Base Local. Por su parte, Pilar Espeso y María J. Pastor parten del análisis de las estrategias de turismo tradicional en un contexto como la selva Lacandona (México), para exponer las luces y sombras de sus efectos en la comunidad Hach Winik a partir de la revisión de la literatura científica sobre los marcos teóricos que han ayudado a abordar el turismo como sistema complejo. Las autoras ponen negro sobre blanco la necesidad de aclarar conceptos antes de lanzarnos a teorizar.

Tres artículos de este libro muestran al Mr. Hyde del turismo, un desencadenador de procesos de empobrecimiento, desigualdad o colapso de actividades tradicionales, que dejan a las comunidades locales con todos los impactos negativos del turismo sin casi ningún contrapeso positivo. 
El artículo de María Eugenia Mellado "Invención de un espacio turístico internacional, dinámicas del poder y respuestas locales", presenta de forma diacrónica el caso del Archipiélago de Las Perlas, en la costa pacífica de Panamá, donde la apuesta por el llamado turismo residencial ha generado un proceso especulativo de elitización del espacio que no ha supuesto mejoras en la calidad de vida de la mayoría de la comunidad local y además ha revitalizado desigualdades históricas.

En "Turismo, gentrificación y patrimonialización de las artesanías en Barichara, 'el pueblo más lindo de Colombia”, Luz Andrea Cote presenta el proceso de gentrificación que inició e impulsó la promoción turística de Barichara y la transformación de esta localidad en uno de los lugares preferidos por la burguesía colombiana para establecer su segunda residencia, expulsando a la población tradicional.

Cerraría esta parte del libro el capítulo de Elena Sánchez Díaz y David Domínguez González "Conflictividad en el desarrollo de un destino turístico emergente. Notas para el estudio de la gobernanza en Mompiche, Ecuador", que constata la tendencia neocolonial del turismo a la improvisación y la depredación cuando éste se desarrolla en ausencia absoluta de políticas públicas - del Estado, en definitiva- y sin la presencia de contrapesos comunitarios organizados con capacidad de influencia.

En el extremo contrario, la deseada imagen del Dr. Jekyll, plasmada en la capacidad del turismo para consolidar la vida económica y cultural de determinadas comunidades agrícolas o empoderar a las mujeres, la presentan las contribuciones de Ernest Cañada, Cristian Terry y Carlos García Palacios.

En "Contribución del turismo comunitario a la economía campesina: la Cooperativa Los Pinos en El Salvador", Cañada describe cómo ante la crisis de precios del café de 2001, los cien socios de una cooperativa cafetera surgida de la Reforma Agraria de los años 80, apostaron por ofertar algunas actividades turísticas y abrir un restaurante. A través de estas acciones han conseguido mejorar su bienestar y seguridad creando nuevos ingresos, nuevos puestos de trabajo y nuevas vías de comercialización para el café que producen.

Por su parte, Terry, en "Turismo Rural Comunitario: $¿$ una alternativa para las comunidades andinas? El caso del agro-ecoturismo del Parque de la Papa (Cusco, Perú)", expone los beneficios de una iniciativa de agro-ecoturismo que involucra a cinco comunidades y que el autor define como de Turismo Rural Intercomunitario frente al habitual Turismo Rural Comunitario. Un trabajo en el que el autor nos invita a reflexionar sobre la hipótesis metodológica, apuntada por Jordi Gascón y Claudio Milano, al preguntarse sobre la viabilidad a largo plazo del proyecto y sus efectos positivos, dados los conflictos intercomunitarios existentes, una vez que los actores externos que daban apoyo logístico y financiero han abandonado el terreno. 
En "Empoderamiento, mujeres indígenas y turismo comunitario en Cota-cachi (Ecuador)", Carlos García Palacios presenta otra cara de los efectos positivos del desarrollo turístico. Su estudio de caso muestra, tanto la resistencia de las instituciones comunitarias indígenas ante los dramáticos cambios en sus modos de vida, como la oportunidad que el turismo comunitario abre para el empoderamiento de la mujer a través del control de la actividad turística y de una buena parte de los beneficios que ésta genera.

Cierra la compilación el capítulo "Debates sobre la patrimonialización del Qhapaq Ñan, el Sistema Vial Andino" de María Luisa Rendón Puertas, un ejemplo en el que podríamos decir que conviven el Dr. Jekyll y el Mr. Hyde del turismo de los que venimos hablando. Se trata de un proyecto multinacional que ha puesto de acuerdo a seis países para conseguir la inclusión del Qhapaq Nan en la Lista de Patrimonio Mundial de la UNESCO, conservar el patrimonio, incentivar la integración o promover el desarrollo a través de la creación de oferta turística. Un proyecto que ha caído en los errores habituales de los procesos de patrimonialización: construcción de identidades estereotipadas, subordinación de los intereses locales a los de los tecnócratas en la gestión y legitimación del patrimonio, etc. Por otro lado, la autora deja ver las ansias de participación y apertura al mundo de la comunidad a través de un proceso en el que el patrimonio cultural se convierte en un valor económico y político que atraviesa la estructura social desde lo trasnacional hasta lo local.

En definitiva, el libro que nos ocupa, El turismo en el mundo rural ¿Ruina o consolidación de las sociedades campesinas e indígenas?, actualiza con ejemplos etnográficos de gran valor discusiones que la antropología del turismo aún no ha conseguido superar. Con ello, anima el debate teórico situando en el centro de los problemas de la disciplina, más allá de las diferencias contextuales de los casos de estudio, la honestidad metodológica y los compromisos ideológicos, conscientes o inconscientes, de los investigadores.

El lector desprevenido puede esperar encontrar en estas páginas etnografías de diferentes lugares del mundo. Sin embargo, una de las limitaciones que encontramos en este texto es de carácter geográfico \derivada seguramente del origen ya comentado de la obra: todos los casos de estudio corresponden al mundo latinoamericano. La inclusión de ejemplos de otras áreas no aportaría necesariamente más valor teórico al libro, pero sí ayudaría a constatar en la práctica que el turismo como fenómeno social y sistema complejo se comporta, en su dualidad, de formas semejantes en cualquier parte del mundo.

En definitiva, una obra que aporta ejemplos relevantes para pensar marcos teóricos de interpretación con los que dialogar sobre un fenómeno que afecta a todos los ámbitos de la sociedad y la vida, y que a pesar de haber sido ampliamente estudiado, sigue sin ser bien comprendido. 


\section{Referencias bibliográficas}

Butler. 1980. “The Concept of an Area Cycle Of Evolution: Implications for Management of Resources". Canadian Geographer 24: 5-12. doi:10.1111/j.1541-0064.1980.tb00970.x. Jafari, Jafar. 1990. "Research and Scholarship: The Basis of Tourism Education”. Journal of Tourism Studies. 1: 33-41. http://www.cabdirect.org/abstracts/19901880625.html. 